\title{
Influence and Mechanism Research of Hydration Heat Inhibitor on Low-Heat Portland Cement
}

\author{
Fujie Jia ${ }^{1,2 *}$, Yan Yao ${ }^{1}$ and Jingyu Wang ${ }^{1,2}$ \\ ${ }^{1}$ State Key Laboratory of Green Building Materials, China Building Materials Academy, Beiijng, China, ${ }^{2}$ Institute of Cement \\ Science and New Building Materials, China Building Materials Academy, Beijing, China
}

OPEN ACCESS

Edited by: Xianming Shi, Washington State University, United States

Reviewed by: Linglin $X u$

Tongji University, China Lei Wang, Xi'an University of Architecture and Technology, China

*Correspondence:

Fujie Jia 15001349855@163.com

Specialty section: This article was submitted to

Structural Materials,

a section of the journal

Frontiers in Materials

Received: 19 April 2021 Accepted: 12 May 2021

Published: 04 June 2021

Citation:

Jia F, Yao Y and Wang J (2021) Influence and Mechanism Research of Hydration Heat Inhibitor on Low-Heat Portland Cement.

Front. Mater. 8:697380.

doi: $10.3389 /$ fmats.2021.697380
A kind of microcapsule sustained-release-type hydration heat inhibitor (MSR) was prepared. The effect of MSR on semi-adiabatic temperature rise, setting time, and strength of low-heat Portland cement was investigated. Microcalorimetry, XRD, SEM, and TG-DSC were used to investigate the mechanism of MSR on hydration of low-heat Portland cement. The results showed that the MSR had good regulating effect on hydration of low-heat Portland cement. When the dosage of MSR was $0.3 \%$, the heat release rate decreased by $10 \%$ and the peak temperature decreased by $52 \%$. The $3 \mathrm{D}$ compressive strength decreased by $50 \%$, and the 28 -day strength was the same as control. The MSR can delay the hydration of low-heat Portland cement by inhibiting the heat release rate of $\mathrm{C}_{2} \mathrm{~S}$ and $\mathrm{C}_{3} \mathrm{~S}$ minerals.

Keywords: low-heat Portland cement, hydration heat inhibitor, microcapsule sustained-release, hydration regulation, mechanism

\section{INTRODUCTION}

Thermal cracking control (Springenchmid et al., 1985; Springenschmid, 1994; Springenschmid, 1994; Springenschmid, 1998; David et al., 2005) has always been a hot subject widely researched by engineers. The hydration heat of cementitious materials is the main factor that leads to thermal cracking of mass concrete. In order to control the temperature rise of cementitious materials in engineering, low-heat Portland cement and mineral admixture (Wang et al., 2021; Wang et al., 2021) are often adopted. For hydraulic concrete, temperature needs to be strictly controlled. Low-heat Portland cement is a good choice due to the low hydration heat. In 1933, during the construction of the Hoover Dam (Katie and Westin, 2010; Timothy, 2010) in the United States, low-heat Portland cement was used to control the risk of concrete thermal cracking. The ASTM IV cement standard set on the basis of low-heat Portland cement of the Hoover Dam is still in use today.

By adjusting the mineral composition of cement clinker and taking $\mathrm{C}_{2} \mathrm{~S}$ as the main mineral, lowheat Portland cement (Mizobuchi, 1998; Yang et al., 2007; Ji et al., 2012; MORI et al., 2012; Li, 2014; QIU et al., 2017; Fan et al., 2018; Wang et al., 2018; Wang et al., 2021) has realized the purpose of reducing the hydration heat release of cement and improving the strength and durability. Using lowheat Portland cement to prepare concrete will effectively reduce the hydration heat. It can significantly reduce the temperature of concrete and avoid the risk of thermal cracking (Mizobuchi, 1998). In order to control the temperature rise in hydraulic engineering, it is often necessary to take other construction measures such as embedded cooling water pipe and mixing with ice in addition to using low-heat Portland cement. All these measures lead to additional construction time and cost. 
TABLE 1 | Chemical composition of low-heat Portland cement.

\begin{tabular}{lcccccccc}
\hline Material & \multicolumn{9}{c}{ Chemical composition (\%) } \\
\cline { 2 - 8 } & Loss & $\mathbf{S i O}_{\mathbf{2}}$ & $\mathbf{A l}_{\mathbf{2}} \mathbf{O}_{\mathbf{3}}$ & $\mathbf{F e}_{\mathbf{2}} \mathbf{O}_{\mathbf{3}}$ & $\mathbf{C a O}$ & $\mathbf{M g O}$ & $\mathbf{S O}_{\mathbf{3}}$ & $\mathbf{R}_{\mathbf{2}} \mathbf{O}$ \\
\hline Low-heat Portland cement & 1.13 & 22.52 & 4.04 & 5.17 & 59.69 & 4.3 & 2.09 & 0.45 \\
\hline
\end{tabular}

Hydration heat inhibitor (Zhao et al., 201310289190; Jia et al., 2013; Zhang et al., 2018; Kim, 2018; Mwaluwinga et al., 1997; Chang Gun and Ismail, 2014; Makul and SuaIam, 2018) is a kind of admixture emerging in recent years. It can regulate the heat release rate of cement to reduce the peak value of temperature. The risk of thermal cracking can be reduced by adding the inhibitor to concrete using Portland cement. It has been applied in many civil construction projects (Jia et al., 2013) to achieve good results. However, no one has studied the control effect of hydration heat inhibitor on lowheat Portland cement in hydraulic mass concrete engineering. For a long time, the pursuit of lower temperature rise or even zero temperature rise of concrete is the ideal of engineers. It is of great significance to the thermal cracking control of mass concrete.

The influence of MSR on the heat release of low-heat Portland cement was investigated by microcalorimetry. The peak cutting effect of MSR on the temperature of low-heat Portland cement was verified by a semi-adiabatic temperature rise test. The microproperties of low-heat Portland cement mixed with MSR were studied by XRD, SEM, and TG-DSC. Furthermore, the influence of MSR on the hydration heat release of cement single mine was proved by a microcalorimeter.

\section{MATERIALS AND METHODS}

\section{Raw Materials}

Low-heat Portland cement with a surface area of $329^{\circ} \mathrm{m}^{2} / \mathrm{kg}$ and a density of $3.12 \mathrm{~g} / \mathrm{m}^{3}$ was used. The chemical composition of cement is listed in Table 1. Figure 1 shows the XRD patterns of single mine. Then, polyethylene wax with 4,000 average molecular weight and $115^{\circ} \mathrm{C}$ melting point was used. Figure 2 shows the GPC curve of the polysaccharide. The molecular weight distribution is shown in Figure 3.

\section{Preparation of MSR}

The MSR was prepared by centrifugal spray granulation with high-molecular-weight polysaccharide as the core material and polyethylene wax as the wall material. The wall material/core material mass ratio was 1 .

The polyethylene wax was placed in a reactor and heated to $120^{\circ} \mathrm{C}$ until it melted into liquid. A uniform liquid mixture was obtained after adding the polysaccharide in proportion through stirring. In order to avoid the breakdown of the polysaccharide into monosaccharides, the temperature of the mixture could not exceed $130^{\circ} \mathrm{C}$ for a long time. The MSR was prepared by centrifugal spray granulation. The particle size of MSR could be controlled according to the rotating speed of the centrifuge.
The MSR with particle size between 0.16 and $0.30 \mathrm{~mm}$ was chosen for this study.

\section{Experimental Methods}

Semi-diabatic Temperature Rise Test of Cement Paste The semi-adiabatic temperature rise test of cement paste was carried out in a foam chamber with a water/cement mass ratio of 0.35 . Figure 4 shows the polystyrene foam box, with an external size of $210 \mathrm{~mm} \times 110 \mathrm{~mm} \times 130 \mathrm{~mm}$, an internal size of $180 \mathrm{~mm}$ $\times 80 \mathrm{~mm} \times 100 \mathrm{~mm}$, and a wall thickness of $15 \mathrm{~mm}$. The temperature sensor was at the center point of the long side, as shown in Figure 4. Experiments were carried out at $(20 \pm 2)^{\circ} \mathrm{C}$. Cement paste of $(2,500.0 \pm 5.0)^{\circ} \mathrm{g}$ was poured into the foam box. Then, the foam box was sealed by tape sealing. The test began, and the temperature was recorded. The test could be terminated when the temperature of cement paste dropped to $22^{\circ} \mathrm{C}$.

\section{Hydration Heat}

The heat release process of cement was measured by a microcalorimeter (TA CO., TAM Air) with a sensitivity of $0.4 \mu \mathrm{J}$ and a baseline stability of $\pm 0.08 \mu \mathrm{W} / \mathrm{h}$. All experiments were kept at $(20 \pm 1)^{\circ} \mathrm{C}$. The water/cement mass ratio (W/C) of the paste was set at 0.5 to achieve the good flowability of cement paste and the good dispersion of MSR. The paste was mixed for $2 \mathrm{~min}$ at 3,200 rpm before putting in the calorimeter.

\section{Microscopic Characteristics}

Phase analysis of cement was investigated by the D8 ADVANCE $\mathrm{X}$-ray diffractometer (Bruker, Karlsruhe, Germany) with $\mathrm{Cu}-\mathrm{K} \otimes$ radiation $(\mathrm{k}=0.154 \mathrm{~nm})$. The scanning range was $5^{\circ}-80^{\circ}$ with a scanning rate of $0.02 \%$.

The hydrate morphologies of cement at 1, 3, 7, and 28d were examined by a Quanta250 Field Emission Scanning Electron Microscope (FEI, Hillsboro, OR, United States). The vacuumoverdried sample was coated with $15 \mathrm{~nm}$ of gold to make it conductive before observation.

A thermal analyzer was used to acquire thermogravimetric (TG) and differential scanning calorimetry (DSC) curves of cement. The heating rate was $10^{\circ} \mathrm{C} / \mathrm{min}$ under nitrogen gas flow, and the weight losses were recorded between room temperature and $1,000^{\circ} \mathrm{C}$.

\section{Setting Time and Compressive Strength Test}

The setting time was determined according to ASTM C191 2001c. The Vicat apparatus was utilized to test the initial and the final setting time.

The compressive strength of cement mortar with MSR at 3, 7, and 28 days was investigated by GB/T 17671-1999. The size of the specimen was $40 \mathrm{~mm} \times 40 \mathrm{~mm} \times 160 \mathrm{~mm}$. The test was carried 

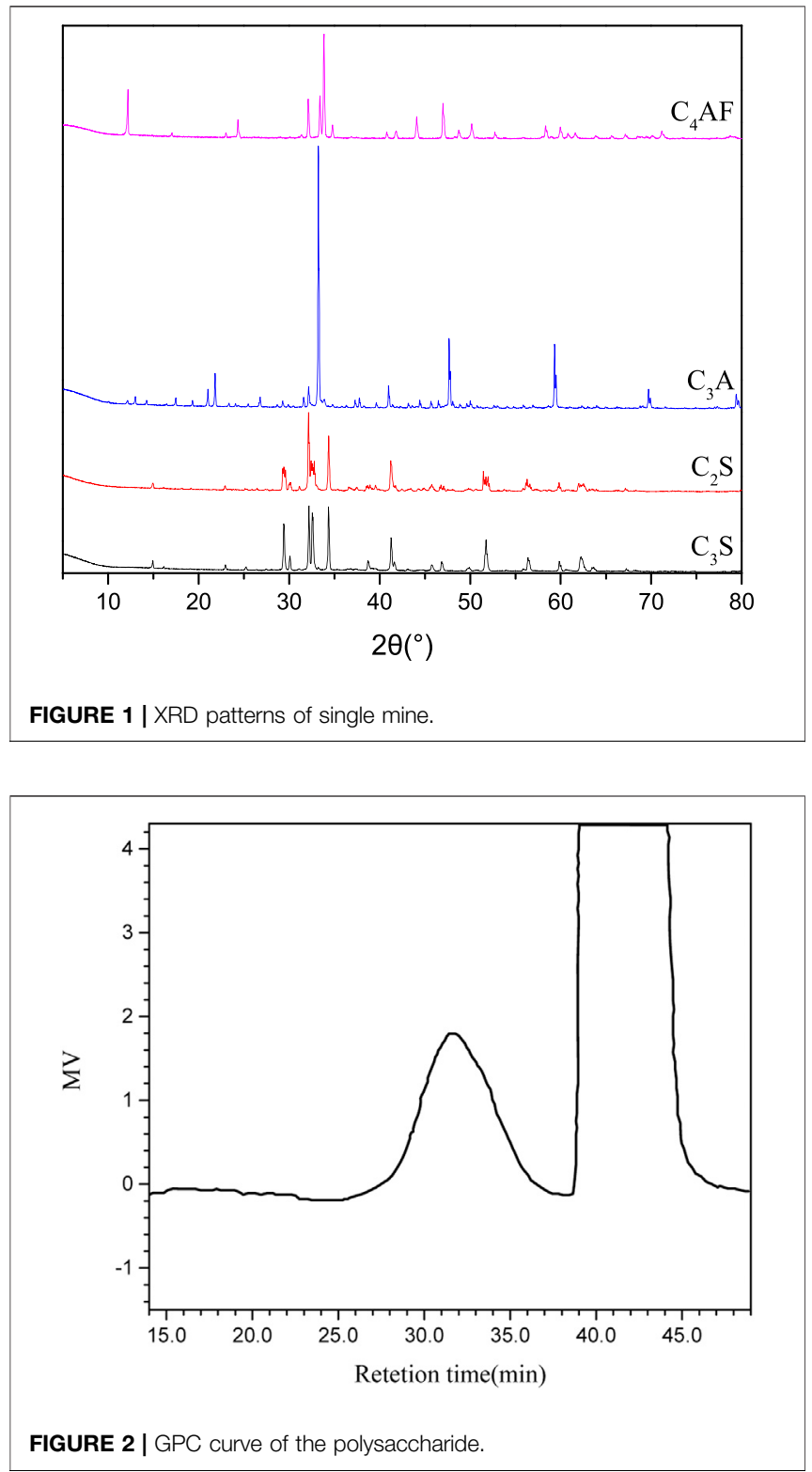

out in an environment with a temperature of $20^{\circ} \mathrm{C}$ and relative humidity of $90 \%$.

\section{RESULTS AND DISCUSSION}

\section{Semi-diabatic Temperature Rise}

Figure 5 shows the semi-adiabatic temperature rise of cement paste with different dosage of MSR. With the increase in MSR, the maximum temperature decreased and the occurrence time of the maximum temperature was delayed. In addition, with proceeding of the reaction, the temperature difference with different dosage of MSR gradually decreased and finally tended to be at the same level. Compared with the reference, the maximum temperature of cement with $0.2 \%$ MSR decreased by $32 \%$ and that with $0.3 \%$ MSR by $52 \%$. The heat release time of $0.2 \%$ MSR was $64 \%$ longer
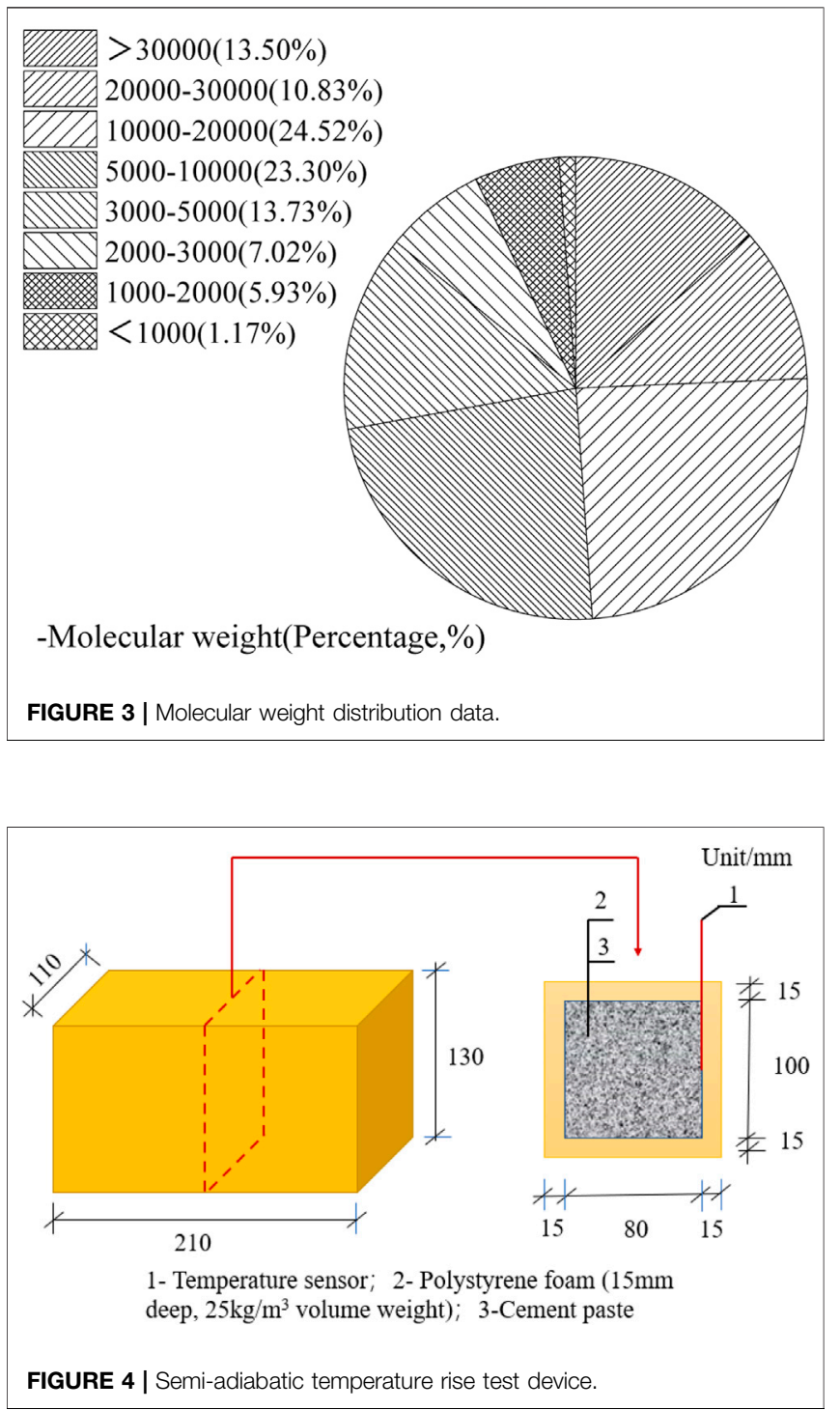

than that of reference. The heat release time of $0.3 \%$ MSR was 1.3 times longer than that of reference. At the same time, it should be pointed out that the temperature with $0.3 \%$ MSR showed double peaks. It indicated that the addition of $0.3 \%$ MSR not only led to the decrease in the maximum temperature but also played a certain regulating role in the maximum temperature. After the MSR was added, the polysaccharide in the MSR was continuously released during the reaction. The hydroxyl groups of the polysaccharide adsorbed on the surface of the cement particles, leading to delay of hydration of the cement. In conclusion, the MSR can significantly reduce the heat release rate and delay the heat release time of the cement. Meanwhile, it can also play a certain role in the heat release process.

\section{Setting Time and Strength}

The setting time will affect the slump loss of concrete. Figure 6 shows the influence of MSR on setting time of low-heat Portland cement. With the addition of MSR, the setting time was prolonged correspondingly. When the MSR content was $0.2 \%$, 


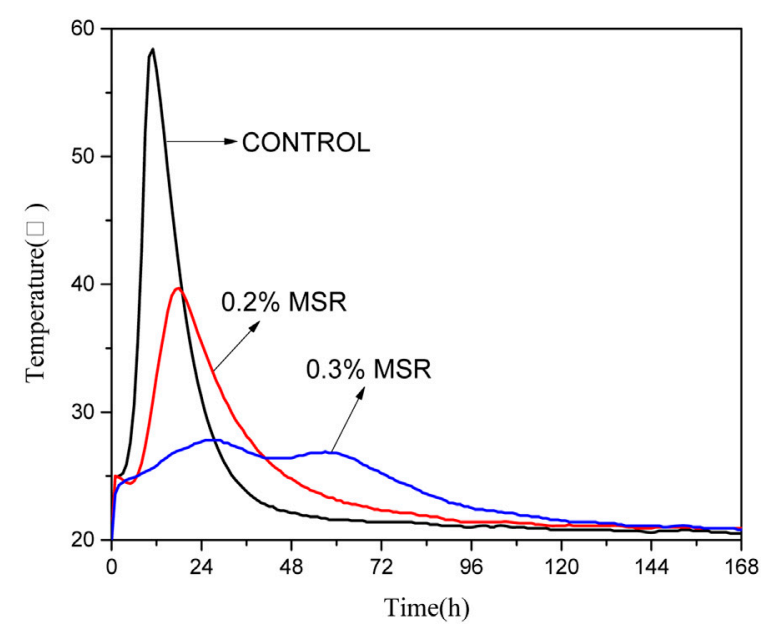

FIGURE 5 | Semi-adiabatic temperature rise of cement paste.

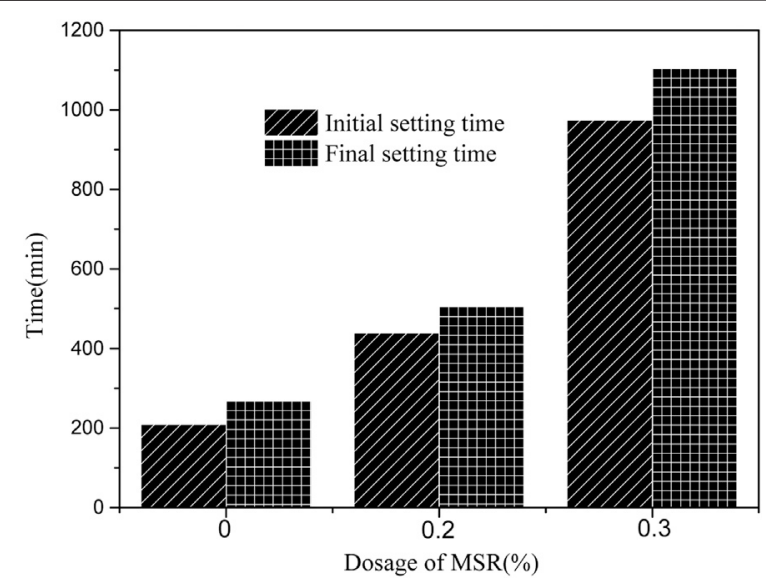

FIGURE 6 | Initial and final setting time determined as per ASTM C191 with different dosage of MSR.

the initial setting time was prolonged $230 \mathrm{~min}$ and the final setting time was prolonged $237 \mathrm{~min}$. When the MSR content was $0.3 \%$, the initial setting time reached $974 \mathrm{~min}$ and the final setting time reached $1104 \mathrm{~min}$. The core material contains some small molecules of monosaccharides, which quickly dissolve into the solution in the early stage. The hydroxyl groups in the monosaccharide adsorb on the surface of the cement particles to form a barrier, which hinders the progress of hydration and causes the delay of setting time. The higher the MSR content, the longer the setting time. The increase in setting time is linearly related to the dosage. The MSR can be used to replace part of the retarder. The equations should be inserted in editable format from the equation editor.

Figure 7 shows the flexural strength and compressive strength of cement mortar with different dosage of MSR. It can be seen that the flexural strength and compressive strength of cement mortar decreased significantly with the increase in MSR at 3 days. The difference in strength between cement mortar with MSR and reference decreased or even disappeared at 28 days. The flexural strength of cement mortar with 0.2 and $0.3 \%$ MSR, respectively, decreased by 30 and $43 \%$ compared with control at 3 days. After 28 days, the flexural strength of cement mortar with $0.2 \%$ MSR decreased by $8 \%$ compared with control, and the flexural strength of cement mortar with $0.3 \%$ MSR decreased by $8 \%$. In 3 days, the compressive strength of cement mortar with $0.2 \%$ MSR decreased by $27 \%$, and the compressive strength of cement mortar with $0.3 \%$ MSR decreased by $50 \%$. At 28 days, the two groups of samples mixed with MSR were equal to the control mortar. In conclusion, the MSR has a negative effect on strength of mortar at an early age, and the effect is positive correlation with the MSR content. With the increase in age, the effect of MSR on strength is gradually weakened. There is no obvious negative effect at 28 days. Due to the influence of MSR on the temperature and strength of cement mortar, the optimal dosage of MSR is $0.3 \%$. With $0.3 \%$ MSR, the heat release rate can be significantly reduced and the 28-day strength cannot be adversely affected.

\section{Mechanism of Hydration Heat Release Rate Reduction}

Heat Release Process and Hydration Kinetics Analysis

Figure 8 shows the hydration rate and cumulative heat of lowheat Portland cement with different MSR dosage. The hydration rate of cement decreased, and the occurrence time of maximum heat release rate was delayed. The effect was positive correlation with the dosage of MSR. Under different MSR contents, the heat release was gradually approached with hydration. Specifically, the maximum heat release rate of the sample with $0.2 \%$ MSR decreased by $12 \%$ compared with control, while the maximum heat release rate of the sample with $0.3 \%$ MSR decreased by $15 \%$ compared with control. In terms of heat release, the exothermic curve of control and the sample with MSR was different in the early stage. As the reaction went on, the hydration heat curve gradually approached and tended to flatten out in the last.

As a porous shell, the wall material creates a barrier between the polysaccharide and the cement phase. The concentration difference between the inside and the outside of the porous shell causes the core material to diffuse to the external solution. The diffusion velocity follows Fick's law. According to Fick's first law, the diffusion flux is proportional to the concentration gradient. At the beginning of diffusion, the concentration gradient is the largest and the diffusion flux is large. With proceeding of diffusion, the concentration gradient decreases. The diffusion becomes slow and finally tends to equilibrium. With the development of diffusion, the concentration of polysaccharide in the cement system increases, while the concentration in microcapsules decreases. The diffusion slows down, and the effect of microcapsules on cement decreases. In conclusion, the MSR significantly inhibits the hydration rate of cement but has no significant effect on the total amount of heat release from cement hydration. The result is consistent with the temperature change of mortar. 

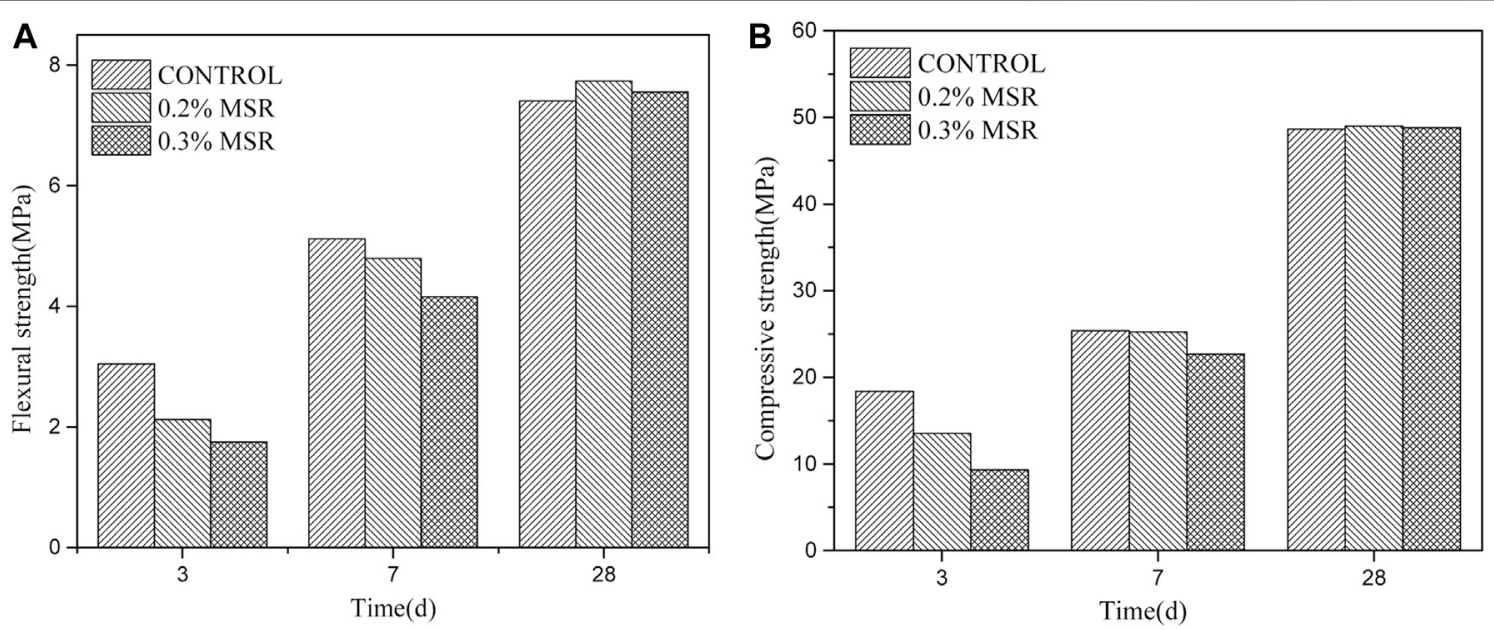

FIGURE 7 | Strength of cement mortar with different dosage of MSR: (A) flexural strength; (B) compressive strength.

At present, the most common experimental method to study the hydration kinetics of cement-based materials is to measure the isothermal hydration exothermic curve of cement-based materials. According to the exothermic characteristics of hydration, the heat release process of cement-based materials can be generally divided into five stages: The rapid reaction period corresponds to the first exothermic peak on the curve of heat release rate. During the induction period (quiescent period), the hydration reaction is relatively inactive. The acceleration period and deceleration period constitute the second exothermic peak on the curve of heat release rate. During the recession (end) period, the rate of heat release gradually approaches zero. Cement mineral composition, cement fineness, water/cement mass ratio, temperature, mineral admixtures, and admixtures affect the reaction rate and duration of each stage of hydration reaction.

Since heat release before the end of the induction period (i.e., the area covered by the first exothermic peak of the exothermic rate curve) generally only accounts for about $5 \%$ of the total heat release, it can be ignored relative to the whole hydration process. In practical engineering, the time interval between concrete mixing and pouring is often more than $0.5 \mathrm{~h}$, and the hydration of cement-based materials has entered the induction period. The influence of the first exothermic peak can be implied in the initial casting temperature of concrete. In research, the influence of the first exothermic peak is usually ignored, that is, the discussion starts from the end of the induction period. In the Krstulovic-Dabic model (Krstulovic and Dabic, 2000) of hydration reaction of cement-based materials, the kinetic equation describing the relationship between the hydration degree and the reaction time can be written as follows.Nucleation and crystal growth, NG:

$$
[-\ln (1-\alpha)]^{\frac{1}{n}}=K_{1}\left(t-\mathrm{t}_{0}\right)=K_{1}^{\prime}\left(t-\mathrm{t}_{0}\right) .
$$

Interactions at the phase boundary, I:
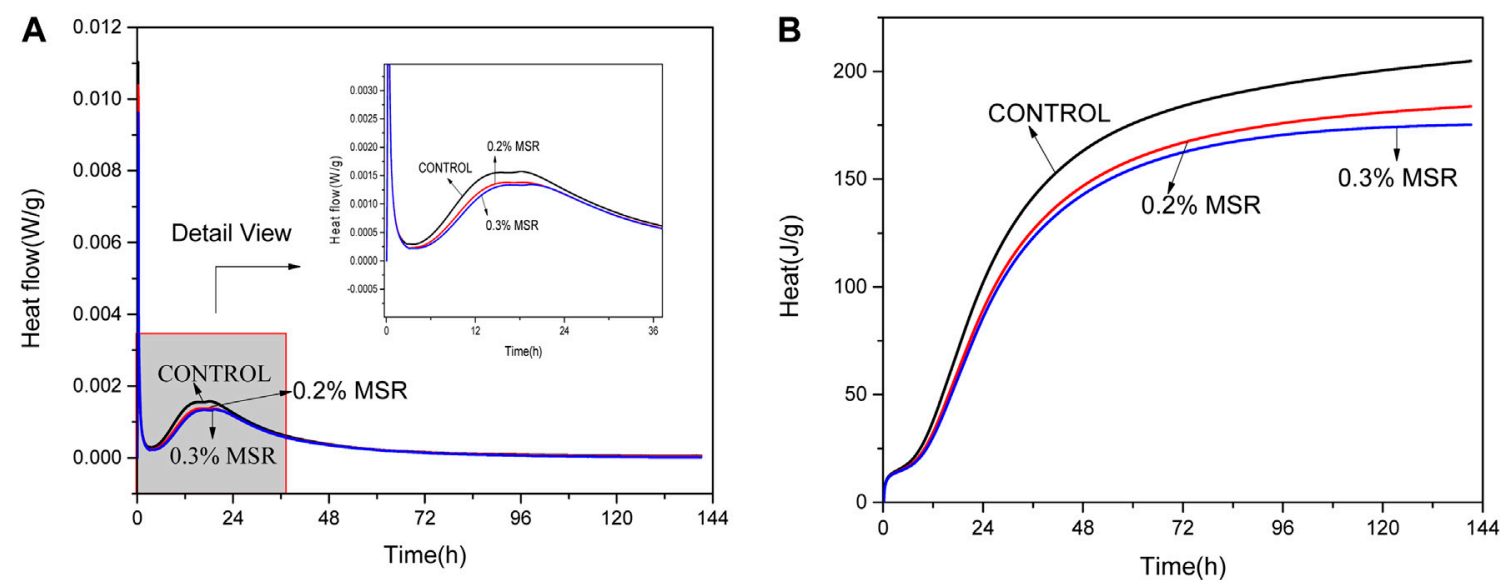

FIGURE 8 | Microcalorimetric curve of cement paste with 0.4 W/C under the constant test temperature of $20^{\circ} \mathrm{C}$ showing (A) heat flow rate and (B) cumulative hydration heat. 
TABLE 2 | Dynamic parameters of the hydration process.

\begin{tabular}{lcccccc}
\hline & $\mathbf{N}$ & $\mathbf{K}^{\prime}{ }_{\mathbf{1}}$ & $\mathbf{K}^{\prime}{ }_{\mathbf{2}}$ & $\mathbf{K}^{\prime}{ }_{\mathbf{3}}$ & $\boldsymbol{\alpha}_{\mathbf{1}}$ & $\mathbf{a}_{\mathbf{2}}$ \\
\hline Control & 2.0535 & 0.0404 & 0.0108 & 0.0051 & 16.4 & 55.6 \\
$0.2 \% \mathrm{MSR}$ & 2.1460 & 0.0398 & 0.0101 & 0.0053 & 14.8 & 59.7 \\
$0.3 \% \mathrm{MSR}$ & 2.1744 & 0.0393 & 0.0095 & 0.0062 & 13.2 & 69.7 \\
\hline
\end{tabular}

$$
\left[1-(1-\alpha)^{\frac{1}{3}}\right]^{1}=\mathrm{K}_{2} \mathrm{r}^{-1}\left(t-\mathrm{t}_{0}\right)=\mathrm{K}_{2}^{\prime}\left(t-\mathrm{t}_{0}\right) .
$$

Diffusion, D:

$$
\left[1-(1-\alpha)^{\frac{1}{3}}\right]^{2}=\mathrm{K}_{3} \mathrm{r}^{-2}\left(t-\mathrm{t}_{0}\right)=\mathrm{K}_{3}^{\prime}\left(t-\mathrm{t}_{0}\right) .
$$

By differentiating Equations 1-3, kinetic equations 4-6 can be obtained, which, respectively, represent the hydration rates of $\mathrm{NG}, \mathrm{I}$, and $\mathrm{D}$ processes.NG process differential expression:

$$
\frac{d \alpha}{d t}=F_{1}(\alpha)=K_{1}^{\prime} n(1-\alpha)[-\ln (1-\alpha)]^{\frac{n-1}{n}} .
$$

I process differential expression:

$$
\frac{d \alpha}{\mathrm{dt}}=\mathrm{F}_{2}(\alpha)=\mathrm{K}_{2}^{\prime} \cdot 3(1-\alpha)^{\frac{2}{3}}
$$

D process differential expression:

$$
\frac{d \alpha}{d t}=F_{3}(\alpha)=\frac{K_{3}^{\prime} \cdot 3(1-\alpha)^{\frac{2}{3}}}{\left[2-2(1-\alpha)^{\frac{1}{3}}\right]}
$$

In Equations 1-6, $a$ is the hydration degree; $K 1\left(K^{\prime} 1\right), K 2\left(K^{\prime} 2\right)$, and $\mathrm{K} 3\left(\mathrm{~K}^{\prime} 3\right)$ are the reaction rate constants of three hydration reactions, respectively; $\mathrm{T}_{0}$ is the end time of the induction period; $\mathrm{n}$ is the reaction order; and $\mathrm{r}$ is the diameter of the particles involved in the reaction.

Figure 9 shows the hydration reaction rate and simulation curve calculated according to Equations 1-3 under different MSR dosage. Heat released before the induction period will not accumulate in the concrete.

It can be seen from Figure 9 that curves $F_{1}(\alpha), F_{2}(\alpha)$, and $F_{3}$ $(\alpha)$ can better piece-wide fit the change in hydration rate of lowheat cement. The hydration kinetics of cement with different MSR contents all experienced three stages: nucleation and crystal growth (NG), interactions at the phase boundary (I), and
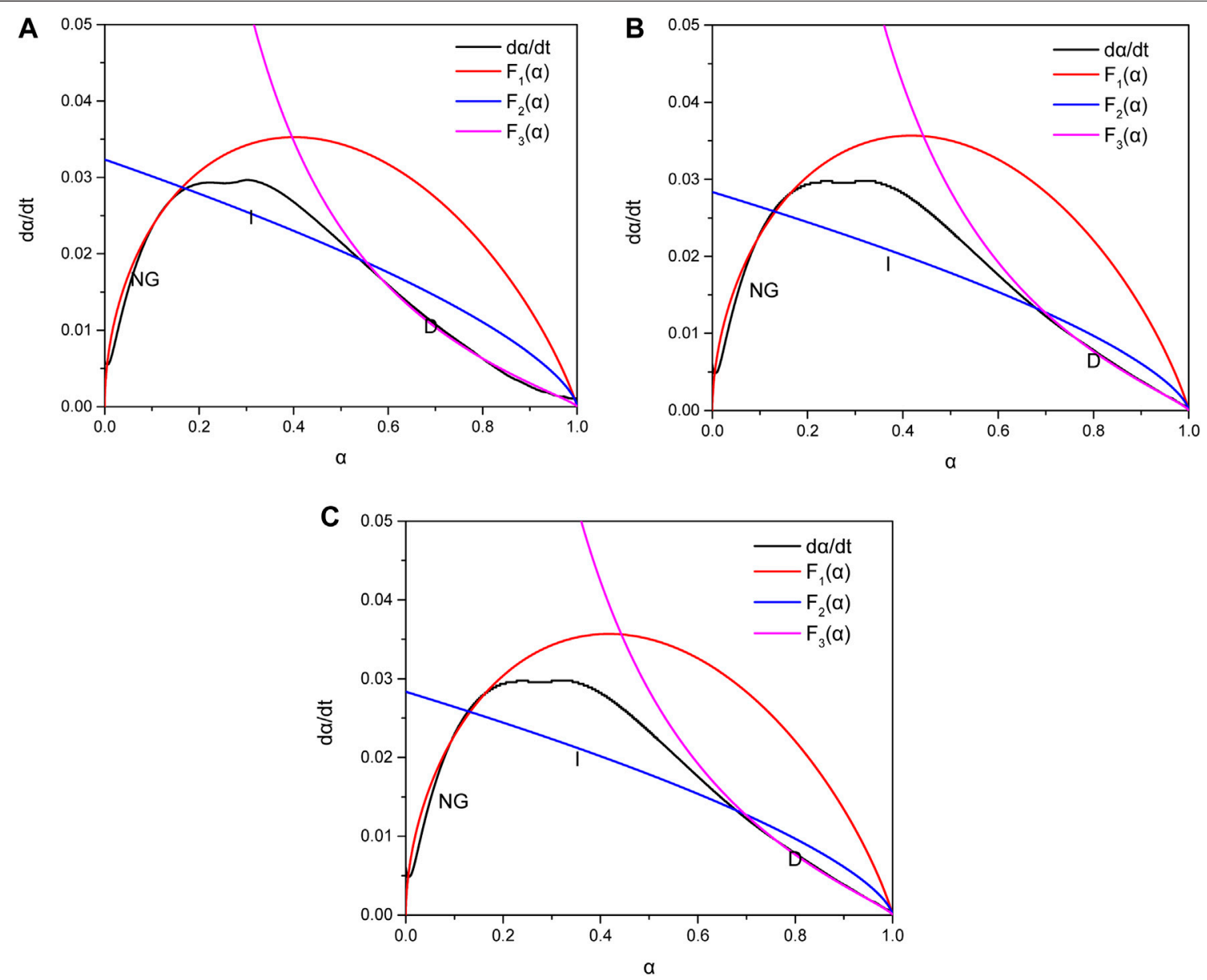

FIGURE 9 | Heat release rate curve showing (A) control, (B) low-heat cement with $0.2 \% \mathrm{MSR}$, and (C) low-heat cement with $0.3 \% \mathrm{MSR}$. 

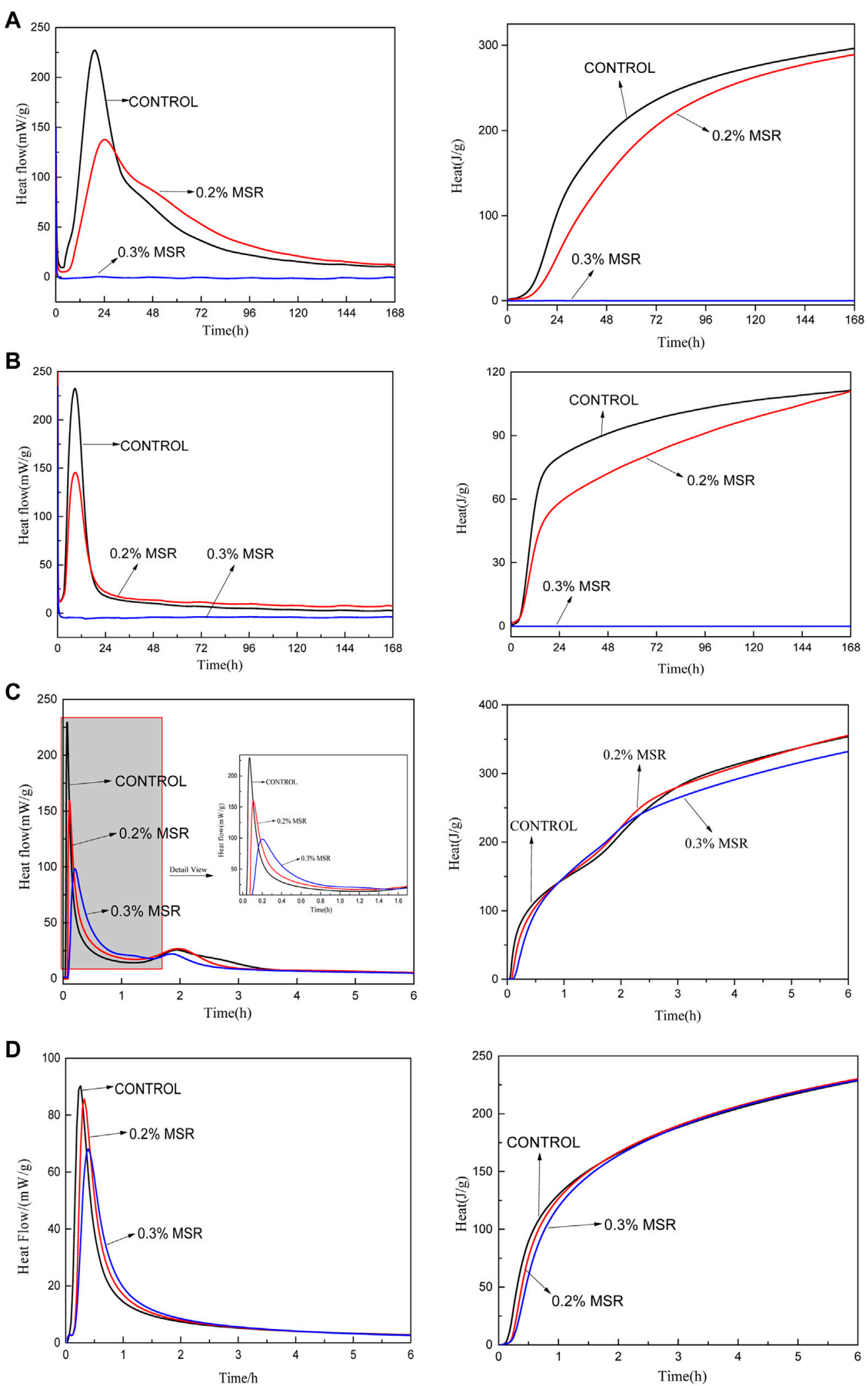

FIGURE 10 | Microcalorimetric curve of single mine paste with $0.4 \mathrm{~W} / \mathrm{C}$ under the constant test temperature of $20^{\circ} \mathrm{C}$ showing heat flow rate and cumulative hydration heat: (A) C3S; (B) C2S; (C) C3A; (D) C4AF. 

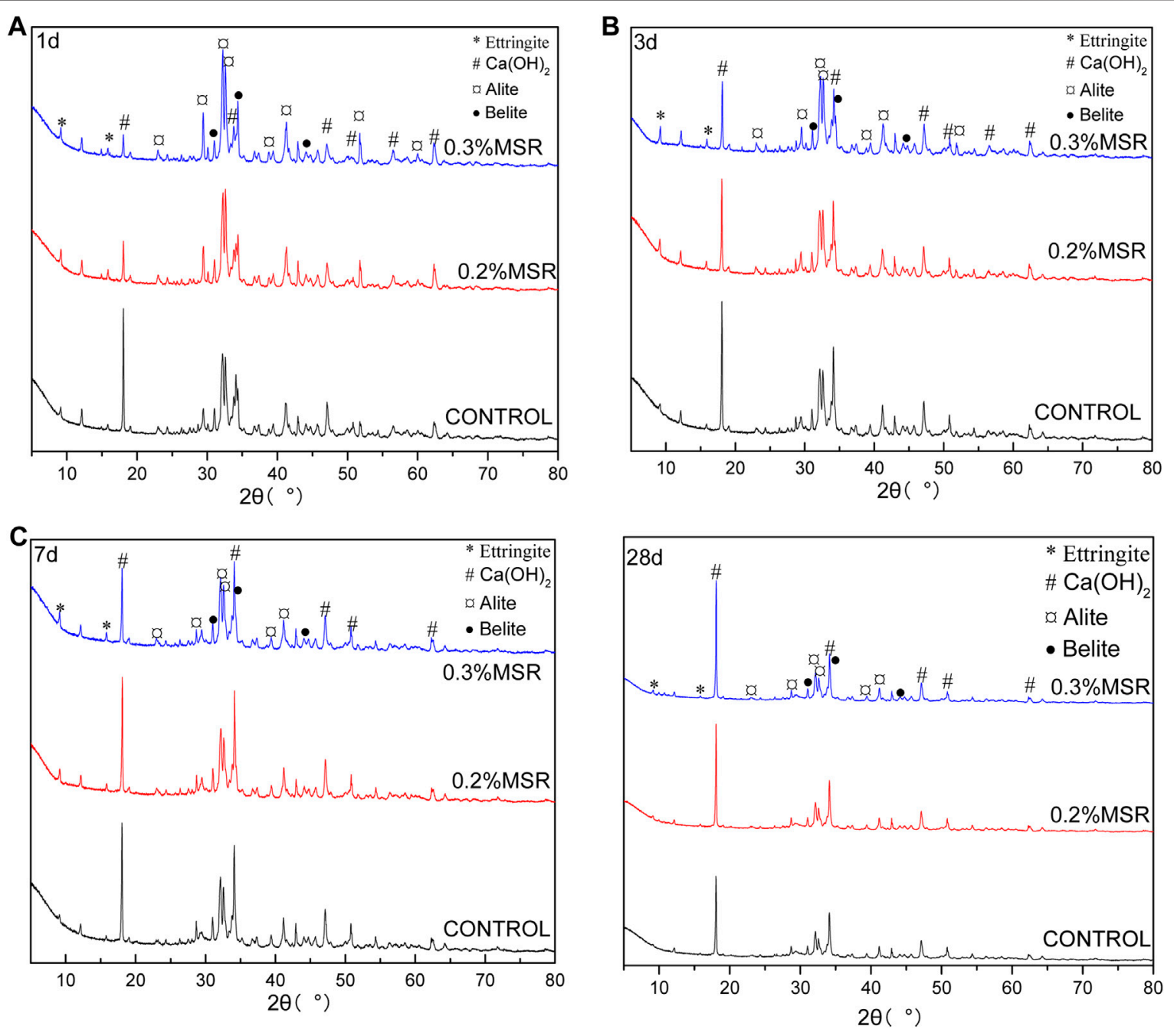

FIGURE 11 | XRD patterns of cement paste with MSR: (A) 1 day; (B) 3 days; (C) 7 days.

diffusion (D). This shows that the hydration of low-heat cement is a complex process and different stages are controlled by different reaction mechanisms. On the contrary, with the increase in MSR content, the hydration reaction rate changed significantly. In the first stage, from the perspective of the chemical reaction order $n$, with the increase in MSR content, the chemical reaction order showed an upward trend, indicating that, with the increase in MSR content, the influence of the MSR concentration involved in the system on the chemical reaction increased. The chemical reaction rate $\mathrm{K}_{1}^{\prime}$ is only related to the reaction temperature and reaction system. In this test, the reaction temperature is certain, and $\mathrm{K}_{1}^{\prime}$ gradually decreases with the increase in MSR content, indicating that the addition of MSR reduces the chemical reaction rate of the system. When the conversion rate is between 0 and $\alpha 1$, the reaction moves from the stage of nucleation and crystal growth (NG) to the phase boundary reaction control stage. As can be seen from Table $2, \mathrm{~K}_{2}^{\prime}$ shows a downward trend with the increase in MSR content. When the reaction degree exceeds $\alpha 2$, the reaction is controlled by diffusion (D), and the increase in
MSR does not cause a significant change in reaction rate $\mathrm{K}_{3}^{\prime}$, indicating that the MSR has no significant effect on the reaction rate during the diffusion stage.

\section{Heat Release Process of Single Mine}

The hydration reaction of cement is essentially the reaction between the active minerals and water. For Portland cement, the mineral composition is mainly $\mathrm{C}_{3} \mathrm{~S}, \mathrm{C}_{2} \mathrm{~S}, \mathrm{C}_{3} \mathrm{~A}$, and $\mathrm{C}_{4} \mathrm{AF}$. The hydration heat tests of $\mathrm{C}_{3} \mathrm{~S}, \mathrm{C}_{2} \mathrm{~S}, \mathrm{C}_{3} \mathrm{~A}$, and $\mathrm{C}_{4} \mathrm{AF}$ with different dosage of MSR were carried out, in order to expound the effect of MSR on minerals. Figure 10 shows the heat flow rate and cumulative hydration heat of cement single minerals with different dosage of MSR. The peak heat release rate of the four minerals decreased significantly after adding the MSR. However, there was no significant effect on the cumulative hydration heat of minerals with the prolongation of age. Specifically, the maximum heat release rate of $\mathrm{C}_{3} \mathrm{~S}$ with $0.2 \%$ MSR reduced by $43 \%$, while there was no obvious heat release within $192 \mathrm{~h}$ when adding $0.3 \% \mathrm{MSR}$. The maximum heat release 

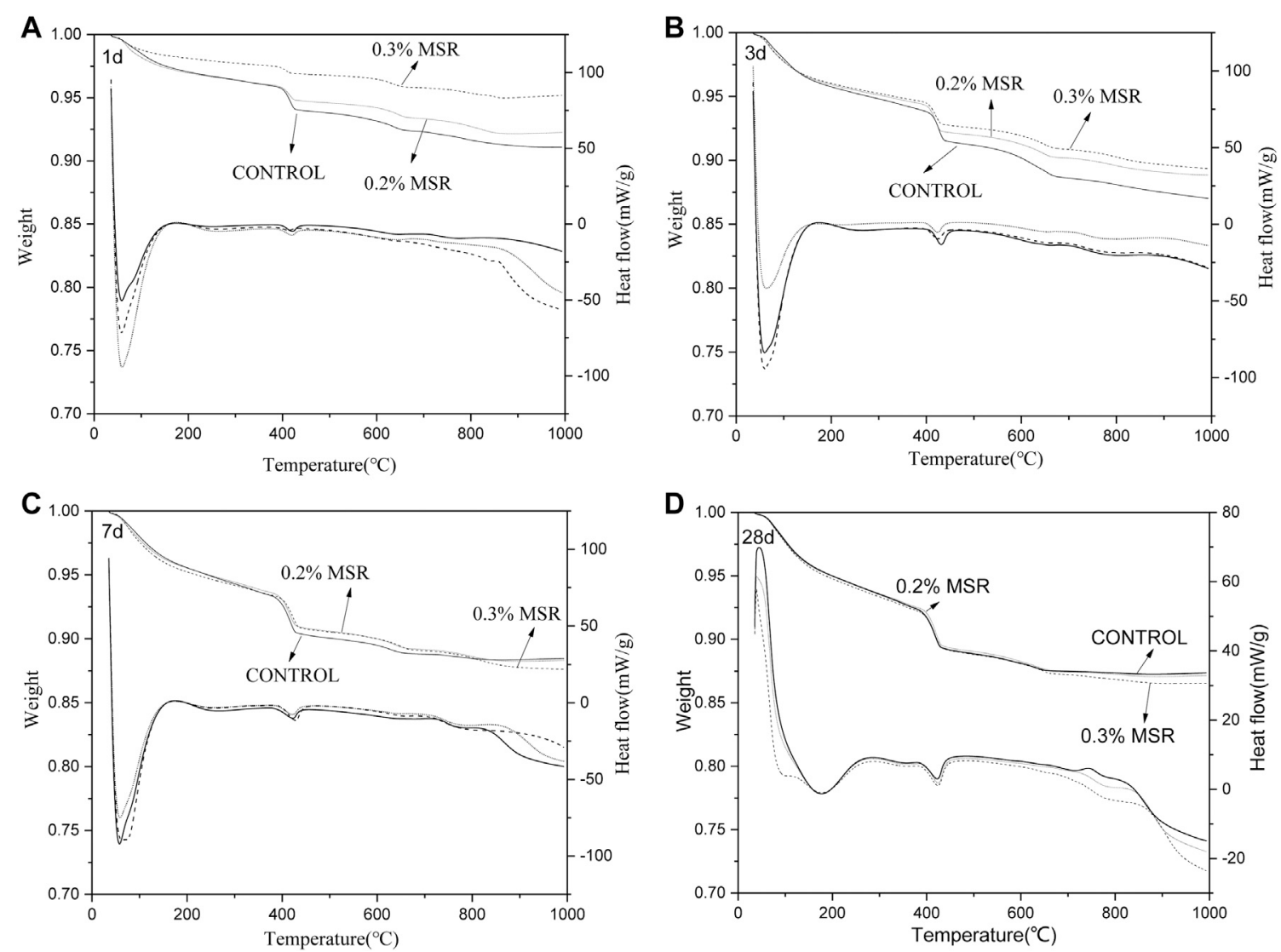

FIGURE 12 | TG-DSC curves of cement with MSR: (A) 1 day; (B) 3 days; (C) 7 days.

rate of $\mathrm{C}_{2} \mathrm{~S}$ with $0.2 \% \mathrm{MSR}$ decreased by $40 \%$ and was the same as that of $\mathrm{C}_{3} \mathrm{~S}$ when adding $0.3 \% \mathrm{MSR}$. The MSR also reduced the reaction rate of $\mathrm{C}_{3} \mathrm{~A}$ and $\mathrm{C}_{4} \mathrm{AF}$. However, $\mathrm{C}_{3} \mathrm{~A}$ and $\mathrm{C}_{4} \mathrm{AF}$ still released heat when adding $0.3 \% \mathrm{MSR}$, but the heat release rate was lower than that of reference. This phenomenon may be attributed to the fast reaction of $\mathrm{C}_{3} \mathrm{~A}$ and $\mathrm{C}_{4} \mathrm{AF}$. In summary, the addition of MSR could only change the heat release rate of minerals but would not affect the cumulative hydration heat of minerals. It should be pointed out that $\mathrm{C}_{3} \mathrm{~A}$ and $\mathrm{C}_{4} \mathrm{AF}$ could still react with $0.3 \% \mathrm{MSR}$. It would enable cement hydration to continue in the early stage, thus leading to the rise of temperature in the system and the development of cement strength. This is consistent with the results of semi-adiabatic temperature development, strength development, and heat release process. The conclusion can be theoretically inferred that the main minerals of MSR were $\mathrm{C}_{3} \mathrm{~S}$ and $\mathrm{C}_{2} \mathrm{~S}$, and the effect of MSR on $\mathrm{C}_{3} \mathrm{~A}$ and $\mathrm{C}_{4} \mathrm{AF}$ was limited under the conditions of this experiment.

As a retarder, the core material of MSR is usually considered to control the setting time by inhibiting the dissolution of solid reactants or the formation of products. The main hydration products of $\mathrm{C}_{3} \mathrm{~S}$ and $\mathrm{C}_{2} \mathrm{~S}$ are $\mathrm{Ca}(\mathrm{OH})_{2}$ and C-S-H gel. During the hydration process, the core material will gradually enter the cement system due to diffusion. The hydroxyl groups of the core material adsorbed on the surface of the cement particles, hindering the contact between cement and water. As a result, this inhibits the reaction of cement. Moreover, the core material can also complexate with the phase containing calcium in the cement. The complexes adsorbed on the surface of calcium

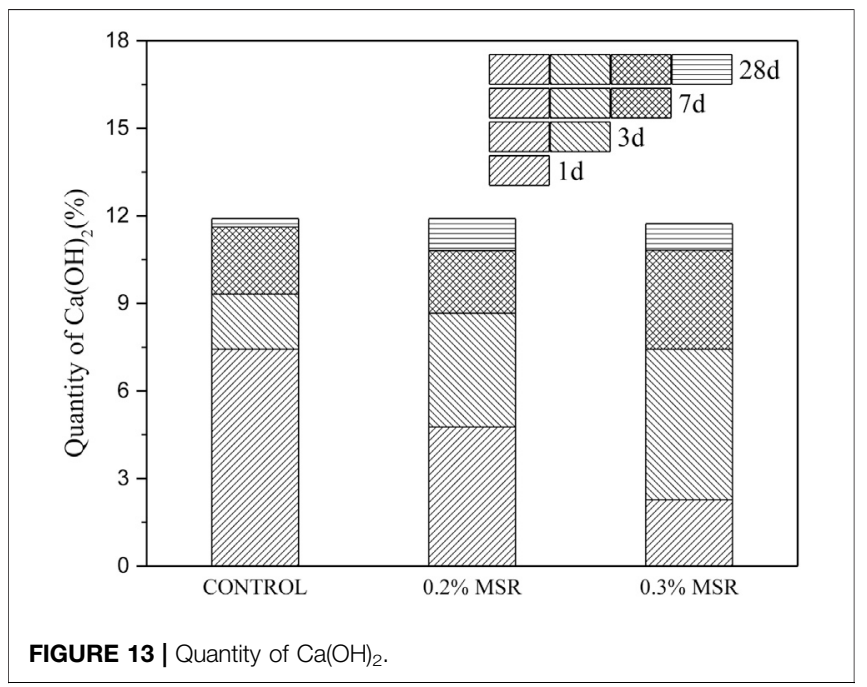




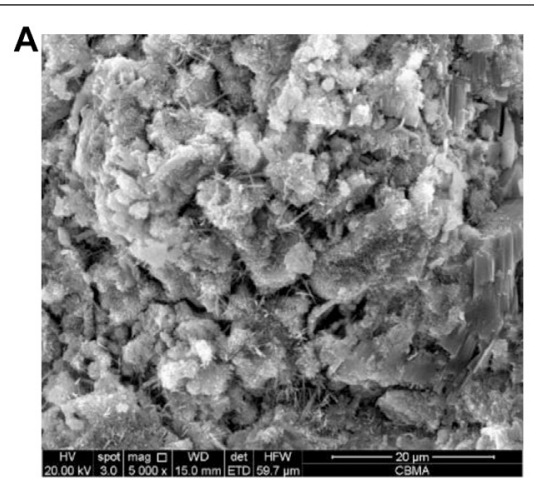

low-heat Portland cement at $1 \mathrm{~d}$

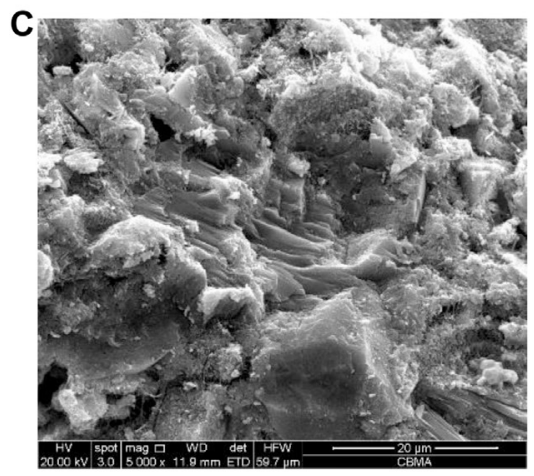

low-heat Portland cement at $7 \mathrm{~d}$

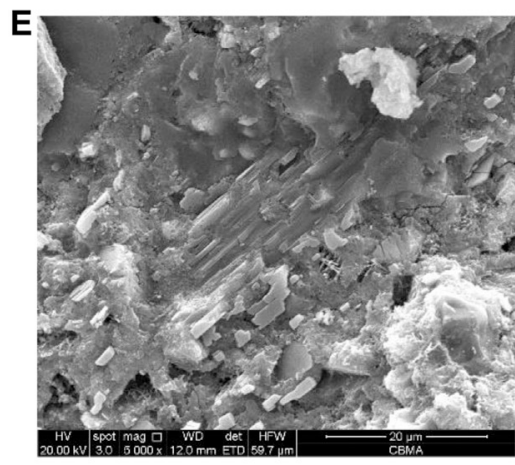

low-heat Portland cement at 28d

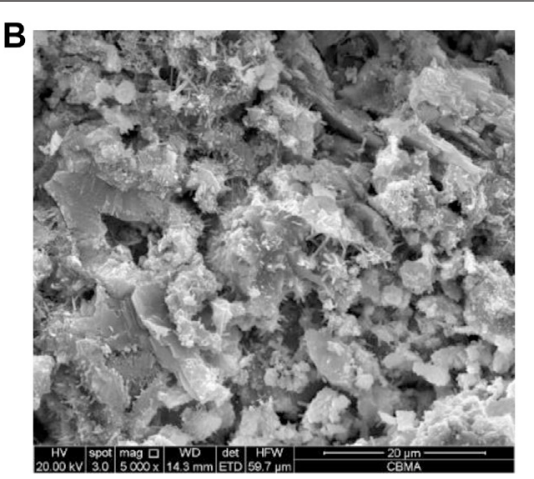

low-heat Portland cement with $0.3 \% \mathrm{MSR}$ at $1 \mathrm{~d}$

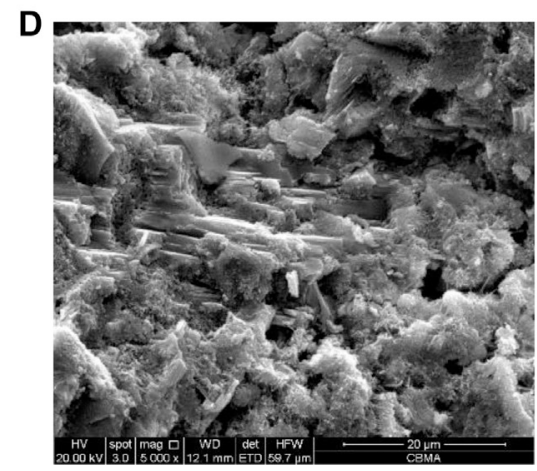

low-heat Portland cement with $0.3 \% \mathrm{MSR}$ at $7 \mathrm{~d}$

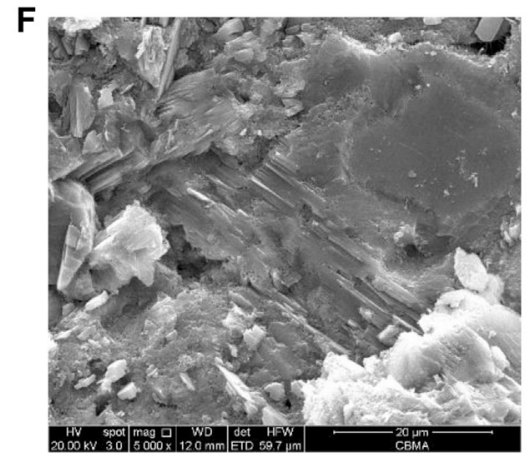

low-heat Portland cement with $0.3 \% \mathrm{MSR}$ at $28 \mathrm{~d}$

FIGURE 14 | SEM diagram of hydration products of cement: (A) low-heat Portland cement at 1d; (B) low-heat Portland cement with 0.3\% MSR at 1d; (C) low-heat Portland cement at 7d; (D) low-heat Portland cement with 0.3\% MSR at 7d; (E) low-heat Portland cement at 28d; (F)low-heat Portland cement with 0.3\% MSR at 28d.

hydroxide and C-S-H gel to prevent further hydration products' formation. In this way, the hydration-inhibiting mechanism of MSR is clarified.

\section{XRD}

Figure 11 shows XRD patterns of low-heat Portland cement with different MSR dosage and curing time. The reaction of cement with MSR could still be carried out, and the MSR would not change the hydration product composition of cement. The main reaction products were ettringite and $\mathrm{Ca}(\mathrm{OH})_{2}$. The effect of MSR on cement hydration could be further analyzed according to ettringite and $\mathrm{Ca}(\mathrm{OH})_{2}$. At the same age, ettringite showed no significant change with the increase in MSR, while calcium hydroxide gradually decreased with the increase in MSR. It indicated that the MSR inhibited the hydration reaction of cement. It should be pointed out that the inhibition was aimed at $\mathrm{Ca}(\mathrm{OH})_{2}$ but had no significant effect on ettringite. With the hydration of low-heat Portland cement, the difference in $\mathrm{Ca}(\mathrm{OH})_{2}$ for cement with different MSR contents gradually decreased. The results were consistent with semi-adiabatic temperature development and strength development. It again confirmed that the MSR could inhibit the hydration rate of cement at an early age, and the inhibition effect became weaker with the increase in hydration. 


\section{TG-DSC}

Figure 12 shows the TG-DSC curves of low-heat Portland cement with different dosage of MSR and different ages. Figure 13 shows the calcium hydroxide content according to TG. The hydration products of cement were $\mathrm{AFm}$ and $\mathrm{Ca}(\mathrm{OH})_{2}$. Compared with control, $\mathrm{Ca}(\mathrm{OH})_{2}$ in cement with $0.2 \%$ and $0.3 \%$ MSR decreased by 36 and $69 \%$ at 1 day, respectively. It indicated that the MSR significantly inhibited the hydration of low-heat Portland cement, and the inhibition effect increased with dosage. After 3 days, the amount of $\mathrm{Ca}(\mathrm{OH})_{2}$ increased, which was only 7 and $20 \%$ lower than that of control. It should be pointed out that the growth rate of cement with $0.3 \%$ MSR was higher than that with $0.2 \%$ MSR. This indicated that the inhibition effect of MSR decreased with age. After 7 days, the hydration products of the cement mixed with $0.2 \%$ and $0.3 \%$ MSR were only $7.0 \%$ lower than those of control. The hydration products of the cement mixed with $0.2 \%$ and $0.3 \%$ MSR were close to each other. The gap between MSR and control was further narrowed at 28 days. This indicated that the inhibition effect of MSR gradually weakened with the reaction, and the dosage did not affect the final hydration process. The results of TG-DSC were consistent with those of XRD. At the same time, the effect of MSR on the hydration reaction of cement was proved again from the perspective of the production amount of $\mathrm{Ca}(\mathrm{OH})_{2}$.

\section{SEM}

Figure 14 shows SEM images of hydration products with different dosage of MSR at different ages. It could be seen that hydration products were still generated at different ages, indicating that the hydration reaction could still proceed normally. The MSR did not change the composition of hydration products. At $1^{\circ}$ day, ettringite was found in both control and low-heat Portland cement with $0.3 \%$ MSR, but the amount of ettringite in control was more. It indicated that cement hydration could still proceed normally after adding the MSR, and the effect of MSR on cement hydration only showed the inhibition of reaction rate. At 7 days, the main product was $\mathrm{Ca}(\mathrm{OH})_{2}$. There was no significant difference in $\mathrm{Ca}(\mathrm{OH})_{2}$ in hydration products between control and low-heat Portland cement with $0.3 \%$ MSR (Figures 14C,D). It indicated that the reaction degree difference between control and low-heat Portland cement with $0.3 \%$ MSR was close at 7 days and 28 days. SEM confirmed the XRD and TG-DSC results.

\section{CONCLUSION}

(1) With the increase in MSR, the semi-adiabatic temperature rise curve changed from a single peak to double peaks. The setting

\section{REFERENCES}

Chang, P., Gun, L., Seung, H., Kuk, C. H., and Ismail, M. (2014). "Study on the Hydration Heat of Mass concrete Mixed with Urea by FEM Analysis [J]." The 6th International Conference of Asian Concrete Federation, Seoul, South Koren, 21-24. doi:10.13140/2.1.4772.6083 time extended. The flexural strength and compressive strength of cement mortar decreased at 3 days and exceeded those of control at 28 days. When the dosage of MSR was $0.3 \%$, the temperature peak time of MSR was delayed by $130 \%$. The maximum temperature was reduced by $52 \%$. As a result, the MSR can regulate the temperature rise without seriously affecting the early strength.

(2) The maximum heat release rate of cement with $0.3 \%$ MSR decreased by $15 \%$ compared with control. Hydration kinetics analysis showed that the MSR reduced the reaction rate of the nucleation and crystal growth stage and the phase boundary reaction stage. The hydroxyl groups in the core material of MSR were released slowly, which had complexation with the calcium phase and adsorbed on the surface of silicate minerals. And it could inhibit the hydration of $\mathrm{C}_{3} \mathrm{~S}$ and $\mathrm{C}_{2} \mathrm{~S}$. Low-heat Portland cement with MSR only adjusted the hydration heat release rate and did not affect the cumulative heat. When the dosage of MSR was $0.3 \%$, the heat release rate decreased by $10 \%$ compared with control.

(3) After the MSR was added, $\mathrm{Ca}(\mathrm{OH})_{2}$ in low-heat Portland cement decreased at an early age and remained the same as control at long age. Ettringite was basically unaffected. The microanalysis by XRD, TG-DSC, and SEM showed that the MSR regulated the heat release process of low-heat Portland cement by regulating the hydration of various minerals.

\section{DATA AVAILABILITY STATEMENT}

The original contributions presented in the study are included in the article/Supplementary Material, and further inquiries can be directed to the corresponding author.

\section{AUTHOR CONTRIBUTIONS}

FJ conducted the majority of the test and wrote the initial draft manuscript. YY was the project coordinator and designed the experiment. JW conducted partial experiment. FJ and JW collected the data and revised the manuscript. All authors contributed to the article and approved the submitted version.

\section{FUNDING}

The authors gratefully acknowledge the funding from the National Key Research and Development Program of China (No. 2017YFB0310102).

David, P. B., Donald, C. J., and Martin, V. M. (2005). The History of Large Federal Dams: Planning, Design, and Construction in the Era of Big Dams[R]. Denver, Colorado: U.S. Department of the Interior, Bureau of Reclamation.

Fan, Q. X., Yang, H. Q., Li, W. W., Springenschmid, R., Breitenbucher, R., Mangold, M., et al. (2018). Comparative Analysis of Thermodynamic Characteristics of Two Low Heat and Medium Heat Portland Cement Concrete [J]. J. Yangtze River Scientific Res. Inst. 35 (12), 133-137. 
Ji, T., Ji, G. J., and Chen, G. X. (2012). Influence of Low-Heat Portland Cement on Properties of Dam Concrete[J]. J. Hydroelectric En-gineering 31 (4), 207-210.

Jia, F. J., Zhang, J. Q., and Nie, F. Y. (2013). Application of Hydration Heat Inhibitor Expansion Agent HCSA-R in Engineering [J]. Expansive agents \& expansive concrete 40 (1), 5-8.

Katie, B., and Westin, J. (2010). "Long-term Properties of Hoover Dam Mass Concrete[C]," in 75th Anniversary History Symposium of Hoover Dam. Las Vegas, Nevada: ASCE, 74-84.

Kim, Hak-Young. (2018). Urea dditives for Reduction of Hydration Heat in Cement Composites[J]. Construction Building Mater., 790-798.

Krstulovic, R., and Dabic, P. (2000). A Conceptual Model of the Cement Hydration Process[J]. Cem Concr Res. 30 (5), 693-698.

Li, G. W. (2014). Investigate the Effect of Low Heat Portland Cement on concrete Dam Volume Stability [J]. Adv. Sci. Techn. Water Resour. 34 (6), 23-26.

Makul, N., and Sua-Iam, G. (2018). Effect of Granular Urea on the Properties of Self-Consolidating concrete Incorporating Untreated rice Husk sh: Flowability, Compressive Strength and Temperature Rise. Construction Building Mater. 162, 489-502. doi:10.1016/j.conbuildmat.2017.12.023

Mizobuchi, T. (1998). Discussion on the Experimental Evaluation of Reducing Effect of thermal Stress of Expansive dditive Based on Uniaxial Restraint Testing Device. JCI Conf. 20 (No.2), 1051-1056.

Mori, K., Fukunaga, T., Sugiyama, M., Iwase, K., Oishi, K., and Yamamuro, O. (2012). Hydration Properties and Compressive Strength Development of Low Heat Cement. J. Phys. Chem. Sol. 73 (11), 1274-1277. doi:10.1016/j.jpcs.2012.07.004

Mwaluwinga, S., Ayano, T., and Sakata, K. (1997). Influence of Urea in concrete. Cement Concrete Res. 27 (5), 733-745. doi:10.1016/s0008-8846(97)00051-3

Qiu, M., Guan, X. M., Liu, S. H., Wang, L., Yang, H. Q., Zhou, S. H., et al. (2017). Lifting Early Strength of Low Heat Cement with Carbonation Technology[J]. Bull. Chin. Ceram. Soc. 36 (10), 3265-3267.

Springenchmid, R., Gierlinger, E., and Kiernozycki, W. (1985). Thermal Stress in Mass concrete: New Testing Method and the Influence of Different Cement. Lausanne, Switzerland, 57-72.

Springenschmid, R. (1998). Avoidance of Thermal Cracking in Concrete at Early Ages[M]. Munich: E\&FN SPON.

Springenschmid, R. (1994). Practical Experience with concrete Technological Measures to void cracking[C]//Thermal Cracking in Concrete at Early Ages. Munich: E\&FN Spon, 377-384.

Springenschmid, R. (1994). Thermal Cracking in Concrete at Early Ages[M]. Munich: E\&FN SPON.
Timothy, P. D. (2010). "Advances in Mass Concrete Technology-The Hoover Dam Studies[C]," in 75th Anniversary History Symposium of Hoover Dam. Las Vegas, Nevada: ASCE, 58-73.

Wang, L., He, T., Zhou, Y., Tang, S., Tan, J., Liu, Z., et al. (2021). The Influence of Fiber Type and Length on the Cracking Resistance, Durability and Pore Structure of Face Slab concrete. Construction building Mater. 282, 122706. doi:10.1016/j.conbuildmat.2021.122706

Wang, L., Jin, M., Wu, Y., Zhou, Y., and Tang, S. (2021). Hydration, Shrinkage, Pore Structure and Fractal Dimension of Silica Fume Modified Low Heat Portland Cement-Based Materials. Construction Building Mater. 272, 121952. doi:10.1016/j.conbuildmat.2020.121952

Wang, L., Luo, R., Zhang, W., Jin, M., and Tang, S. (2021). Effects of Fineness and Content of Phosphorus Slag on Cement Hydration, Permeability, Pore Structure and Fractal Dimension of concrete. Fractals 29 (2), 2140004. doi:10.1142/S0218348X21400041

Wang, L., Yang, H. Q., Zhou, S. H., Chen, E., and Tang, S. W. (2018). Hydration, Mechanical Property and C-S-H Structure of Early-Strength Low-Heat Cement-Based Materials. Mater. Lett. 217, 151-154. doi:10.1016/j.matlet. 2018.01.077

Yang, H. Q., Li, W. W., Wang, Y. C., Chang, P., Gun, L., Seung, H., et al. (2007). Application of Low Heat Portland Cement in Three Gorges Project [J]. Yangtze River 38 (1), 10-13.

Zhang, H., Wang, W., Li, Q., Tian, Q., Li, L., and Liu, J. (2018). A Starch-Based dmixture for Reduction of Hydration Heat in Cement Composites. Construction Building Mater. 173, 317-322. doi:10.1016/j.conbuildmat.2018. 03.199

Zhao, S. Z., Liu, l., Jia, F. J., Li, C. C., and Wu, X. N. (201310289). A Kind of Hydration Heat Suppression concrete Expansion Material, Preparation Method and pplication [P]. Beijing: China Patent for Invention, 9.

Conflict of Interest: The authors declare that the research was conducted in the absence of any commercial or financial relationships that could be construed as a potential conflict of interest.

Copyright (c) $2021 \mathrm{Jia}$, Yao and Wang. This is an open-access article distributed under the terms of the Creative Commons Attribution License (CC BY). The use, distribution or reproduction in other forums is permitted, provided the original author(s) and the copyright owner(s) are credited and that the original publication in this journal is cited, in accordance with accepted academic practice. No use, distribution or reproduction is permitted which does not comply with these terms. 